\title{
Ensino do processo de análise de assunto para indexação com aplicação de um modelo de leitura: estudo de avaliação comparada em cursos de graduação em Biblioteconomia do Brasil
}

Teaching subject analysis processes for indexing applying a reading model: a comparative study of two Librarianship undergraduate courses in Brazil

\section{Mariângela Spotti Lopes FUJITA (1) y Glória Isabel Sattamini FERREIRA (2)}

(1) Universidade Estadual Paulista Júlio de Mesquita Filho, UNESP, Departamento de Ciência de Informação, Av. Hygino Muzzi Filho, 737, Campus Universitário, CEP. 17525900, Marília, SP, Brasil, CaixaPostal: 421, fujita@marilia.unesp. br; (2) Universidade Federal do Rio Grande do Sul, UFRGS, Departamento de Ciências da Informação da Faculdade de Biblioteconomia e Comunicação, Rua Ramiro Barcelos, 2705, Bairro Santana, CEP 90035-007, Porto Alegre, RS, Brasil, gloria.ferreira@ufrgs.br

\begin{abstract}
Resumen
El modelo de lectura documentaria presenta una propuesta metodológica de análisis temático, dirigida, primordialmente, a la enseñanza de la indización para facilitar la disminución de las inherentes dificultades a la tarea. En este sentido, se realizó un estudio de evaluación comparado del modelo de lectura documentario con 4 alumnos de lo Curso de Biblioteconomía de la Universidad Estadual Paulista (UNESP) del Campus de Marília, y 4 alumnos de la Universidad Federal do Rio Grande do Sul (UFRGS), Brasil. Después de la lectura del manual de procedimientos, los alumnos realizaron un análisis de asunto conforme orientación del Modelo de Lectura. Los resultados obtenidos de las dos aplicaciones demostraron que la categorización utilizada por el Modelo de Lectura Documentaria colabora, de modo general, a la uniformidad de los conceptos identificados y los procedimientos, estableciendo claramente cuáles son las etapas a ser realizadas y cuál es la secuencia. Se concluye con la necesidad de mantener la colaboración entre docentes para mejorar la enseñanza de la indización.
\end{abstract}

Palabras clave: Lectura documentaria. Análisis de asunto. Indización.

\section{Introdução}

Entende-se como indexação o ato de descrever e identificar um documento de acordo com seu assunto. $\mathrm{Na}$ indexação, os conceitos são extraídos do documento durante o processo de análise realizado mediante atividade de leitura e, então, traduzidos para os termos utilizados na

\begin{abstract}
The documentary reading model presents a methodological proposal for teachning indexing in Librarianship undergraduated courses, aimed at the improvement of the indexer initial education and systematization of the subject analysis process in order to decrease the difficulties concerning the task. Thus, a study of compared evaluation of documentary reading model was carried out with 4 students of Librarianship course from Universidade Estadual Paulista (UNESP), Marília Campus, SP, and 4 students from Universidade Federal do Rio Grande do Sul (UFRGS), Brasil. After reading the procedures handbook, the students carried out the subject analysis according to the Reading Model. The results showed that the categorization used by the Documentary Reading Model cooperates, generally, toward the uniformity of the identified concepts and the procedures of subject analysis, making clear which are the stages to be carried out and in which sequence. It is concluded that the teaching of the subject analysis process needs a collective reflection among teachers of Librarianship courses to share methodological and theoretical knowledge.
\end{abstract}

Keywords: Documentary reading. Subject analysis. Indexing.

indexação. Realizar esse processo cabe ao indexador, enquanto leitor profissional, que tem um objetivo definido em relação a sua tarefa: a representação temática por termos livres ou controlados, que sejam adequadamente recuperados por interfaces de buscas em sistemas de recuperação da informação de unidades de informação. Lancaster (2004) afirma que o pro- 
pósito principal da elaboração de índices e resumos é construir representações de documentos publicados numa forma que se preste a sua inclusão em algum tipo de base de dados impressa ou em formato eletrônico.

Refletir sobre o propósito da Indexação é importante aos Professores de Indexação, uma vez que estes formam os indexadores para atuar profissionalmente em unidades de informação. O trabalho do indexador é cada vez mais relevante e o âmbito de sua atuação está aumentando em razão do crescimento da literatura publicada em forma impressa e eletrônica.

A identificação e a seleção de conceitos presentes no conteúdo do documento são realizadas durante e por meio da leitura determinando o processo de compreensão e constituindo-se em fase, decididamente, importante da análise de assunto para indexação.

A formação do profissional bibliotecário como indexador necessita dos aportes teóricometodológicos específicos sobre leitura documentária, dotados dos aspectos cognitivos e lingüísticos, dentro da área curricular de Organização da Informação de cursos de Biblioteconomia. Com esta formação, o futuro indexador poderá estar mais capacitado não só para o desempenho da atividade, mas para o seu autodesenvolvimento.

Nesse sentido, o Modelo de Leitura Documentária para a indexação de artigos científicos apresenta uma proposta metodológica de análise de assunto para indexação, dirigida, primordialmente, ao ensino de indexação na graduação em Biblioteconomia com as finalidades de aprimoramento da formação inicial do indexador e sistematização do processo de análise de assunto para diminuição das dificuldades inerentes à tarefa. Contudo, é preciso que Professores de Indexação proponham-se a avaliar o Modelo de Leitura Documentária com a finalidade de implantá-lo em conteúdos curriculares dos Cursos de Biblioteconomia e divulgar a importância e a influência que a leitura exerce sobre todo o desempenho da atividade de organização e representação da informação documentária.

Com essa proposição, esta pesquisa, relata o desenvolvimento e resultados obtidos do estudo de avaliação comparada do uso e aplicabilidade do Modelo de Leitura Documentária por alunos de graduação e professores dos Cursos de Biblioteconomia da Universidade Estadual Paulista (UNESP) - Campus de Marília e da Universidade Federal do Rio Grande do Sul (UFRGS), Brasil, com o objetivo de analisar o uso de metodologias no ensino do processo de análise de assunto de documentos.

\section{O ensino do processo de indexação nos conteúdos curriculares dos Cursos de Biblioteconomia da UNESP e da UFRGS}

O Curso de Biblioteconomia da UNESP, implantado em 1977, já passou por várias alterações curriculares em função da evolução da área de Ciência da informação. A última alteração curricular ocorreu em função das Diretrizes Curriculares para os Cursos de Biblioteconomia, aprovadas em 03/04/2001 mediante Parecer 492/2001 CNE/CES da Câmara Superior de Educação do Conselho Nacional de Educação.

Os conteúdos do curso distribuem-se em conteúdos de formação geral, destinados a oferecer referências cardeais externas aos campos de conhecimentos próprios da Biblioteconomia, e em conteúdos de formação específica, que constituem o núcleo básico no qual se inscreve a formação de bibliotecários.

Os conteúdos curriculares de formação geral, formação profissional e Instrumentalidades estão subdivididos em áreas curriculares e cada uma, por sua vez, em disciplinas de núcleo comum (a ser cursado por alunos de Biblioteconomia e Arquivologia conjuntamente) e disciplinas específicas (a ser cursado pelos alunos de Biblioteconomia separadamente).

O núcleo de formação profissional está subdividido em cinco áreas curriculares: 1 . Fundamentos de Ciência da Informação; 2. Organização e Recuperação da Informação; 3 . Gestão da Informação; 4. Tecnologias em Informação 5. Recursos e Serviços de Informação.

A área curricular de Organização e Recuperação da Informação contém as disciplinas:

\begin{tabular}{lcc}
\hline Disciplinas & Ano & Créditos \\
\hline Análise Documentária & 1 & 4 \\
Catalogação & 1 & 2 \\
Elementos de Lógica & 1 & 2 \\
Lingüística e Documentação & 1 & 4 \\
Catalogação Automatizada & 1 & 6 \\
$\begin{array}{l}\text { Linguagens Documentárias } \\
\text { Alfabéticas }\end{array}$ & 2 & 4 \\
$\begin{array}{l}\text { Linguagens Documentárias } \\
\text { Hierárquicas }\end{array}$ & 2 & 4 \\
Indexação e Resumos & 3 & 4 \\
Leitura Documentária & 3 & 2 \\
\hline
\end{tabular}

Quadro 1. Disciplinas da área curricular de Organização e Recuperação da Informação

A disciplina "Indexação" (30 horas/aulas - $2^{\circ}$ semestre), antecedida pela Análise Documentá- 
ria $\left(1^{\circ}\right.$ ano) é ministrada no $3^{\circ}$ ano do Curso de Biblioteconomia da UNESP após as disciplinas de Linguagens Documentárias (ministradas no $2^{\circ}$ ano do Curso) e em continuidade ao conteúdo ministrado na disciplina "Leitura documentária" (30 horas/aulas - $1^{\circ}$ semestre) com enfoque na atividade de indexação dentro do contexto do Tratamento temático de conteúdo (item 1 do Anexo A). Para isso, o conteúdo programático da disciplina de "Indexação" deverá explorar o contexto e a função da indexação (item 2 do Anexo A) em uma abordagem sociocognitiva, para que o aluno tenha contato com o contexto real de unidades de informação mediante elaboração do trabalho de política de indexação (item 3 do Anexo A) na biblioteca do Campus de Marília para a área de Fonoaudiologia, e contato com a política de indexação vigente no manual de indexação da base de dados LILACS para realizar exercícios de indexação de artigos de periódicos da área de Fonoaudiologia (item 2 do Anexo A).

O processo de indexação (item 4 do Anexo A) será analisado na perspectiva teórica e metodológica da identificação e seleção de conceitos em análise de assunto para esclarecer a influência da tematicidade e das concepções de análise de assunto na abordagem sociocognitiva da indexação.

Em continuidade, é demonstrada de forma prática a metodologia para realizar o processo de identificação e seleção de conceitos em análise de assunto. O Modelo de leitura documentária para a indexação de artigos científicos é a metodologia utilizada para aplicação prática de indexação com artigos da área de Fonoaudiologia, considerando-se a perspectiva da abordagem sociocognitiva, na qual o aluno, antecipadamente, obteve contato com o contexto da unidade de informação e da demanda do usuário de Fonoaudiologia do Campus de Marília quando realizou os trabalhos do item 3 sobre Política de Indexação.

Nessa aplicação prática, o aluno também terá contato com a linguagem documentária específica da área de Fonoaudiologia para completar seu conhecimento sobre a área, e realizar a atividade de indexação ciente do contexto e da demanda de informação. A atividade de indexação com o Modelo de leitura será feita na dinâmica de interação entre dois alunos como recomendado pelo Protocolo Verbal Interativo para que troquem experiências e acelerem o processo de aprendizagem da metodologia. Por último, serão realizados seminários sobre indexação automática com base nos capítulos do livro de Isidoro Gil Leiva.
No Curso de Biblioteconomia da UFRGS as atividades de Análise de Assunto e Leitura Documentária são focalizadas nos programas das disciplinas de Fundamentos de Organização e Tratamento da Informação ( $1^{\circ}$ semestre, 30h/a) e Introdução à Representação Temática $\left(2^{\circ}\right.$ semestre, 60h/a). $O$ estudo de instrumentos de indexação é realizado em outras disciplinas da área de Representação Temática, como na disciplina de Linguagens de Indexação I (CDD) e Linguagens de Indexação II (CDU). Nessas disciplinas os alunos têm oportunidades para práticas de análise de assunto antes de escoIherem a notação do sistema de classificação documentária.

$\mathrm{Na}$ FABICO/UFRGS a Indexação é parte da área de Organização e Tratamento da Informação cuja organização dos conteúdos objetiva oferecer uma visão integrada do princípio de que a Indexação envolve os processos de Representação Descritiva e Representação Temática. Com este sentido os conteúdos desta área foram organizados em três grandes categorias: 1. Fundamentação teórica. 2. Processo de representação documental. 3. Produtos de recuperação da Informação. A seqüência das disciplinas é mostrada no gráfico em Anexo B.

$\mathrm{Na}$ Fundamentação Teórica encontram-se conhecimentos específicos da própria área como os advindos da Filosofia, Lógica e Administração (Política, Diretrizes). Na categoria Processo de Representação Documental, encontram-se os princípios, métodos, instrumentos, técnica e teorias específicas da representação descritiva e da representação temática. Na categoria Produtos de Recuperação da Informação é focalizada a construção dos instrumentos de acesso à informação. A existência destas três categorias permite uma visão integrada do processo de organização e tratamento da informação.

Principalmente no primeiro semestre na disciplina de Fundamentos de Organização e Tratamento da Informação e no segundo, na disciplina de Introdução à Representação Temática, os exercícios exigem a aplicação da característica conforme critérios da Lógica, a construção de Mapas Conceituais nos quais visualizam as facetas, classes subordinadas e coordenadas, bem como as relações entre os conceitos. Além disto, nestas duas disciplinas os alunos têm oportunidade de práticas de representação de assunto, tanto de resumos como de índices construídos com palavras-chaves.

Na prática de indexação são seguidas as etapas propostas pela NBR-12676 da ABNT - Associação brasileira de Normas Técnicas. Os alunos efetuam análise de assunto dos documentos 
(livros e artigos de periódicos) efetuando a representação dos assuntos por meio de palavras-chave. Estes exercícios são efetuados na Biblioteca Laboratório e também, algumas vezes no Laboratório de Informática onde são utilizados para análise artigos de periódicos acessados em Base de Dados.

Como recursos auxiliares, tanto na elaboração de resumos como na prática de indexação utiliza-se a elaboração de mapas conceituais do texto a ser analisado. Observa-se que o emprego destes instrumentos permite ao aprendiz visualizar os principais tópicos do texto a serem incluídos em resumos e a serem representados por palavras-chave facilitando, também, a capacidade de elaboração da análise e da síntese cujo resultado vai depender também dos conhecimentos prévios dos alunos.

Não havia, até então, na UFRGS o uso de metodologia do Modelo de leitura documentária para a indexação de artigos científicos como a proposta pelo presente estudo, que inclui a identificação de categorias na análise de assunto, o que poderá auxiliar os alunos neste aprendizado, uma vez que fornece um maior detaIhamento e balizamento ao procedimento de análise de assunto.

Constata-se que as disciplinas de indexação na UNESP e na UFRGS têm objetivos e conteúdos curriculares aproximados, embora a seqüência de oferecimento da disciplina tenha diferenças, enquanto na UNESP é oferecida no $3^{\circ}$ ano, na UFRGS é oferecida no $1^{\circ}$ ano. $O$ método de análise conceitual com exploração da estrutura textual do Modelo de Leitura Documentária oferece uma nova proposta metodológica para o ensino do processo de indexação de artigos científicos na disciplina de indexação da UFRGS.

O interesse desta pesquisa é o compartilhamento de experiências que demonstrem a necessidade de aprimoramento do ensino de indexação no que tange à diminuição das dificuldades e da complexidade que envolve a leitura documentária para análise de assunto de artigos científicos.

\section{A metodologia do Modelo de Leitura Documentária em indexação}

Os resultados derivados da observação e da fundamentação teórica da leitura proporcionaram os subsídios necessários à elaboração de uma metodologia formal para a leitura documentária na indexação de textos científicos. A proposta de combinação de estratégias de explora- ção de estruturas textuais e de abordagem sistemática para identificação de conceitos partiu da observação, mediante protocolos verbais dos indexadores, em estudo realizado por Fujita (2003), de que essas duas estratégias não eram acionadas em conjunto, o que culminou na elaboração de um Modelo de Leitura Documentária para textos científicos (Fujita \& Rubi, 2006).

O estudo da leitura documentária, realizado por Fujita (2003), teve como ponto de partida a dificuldade do indexador frente à complexidade da análise de assunto de documentos com objetivo de indexação, considerando-a, da mesma forma, que a dificuldade de um leitor frente a um texto com o qual é preciso interagir, a distância, com as idéias de um autor, acrescendo aí, a variável contexto do sistema de informação, além da formação e atuação profissional do indexador.

Inicialmente, demonstra o indexador visto como leitor, a partir de uma perspectiva cognitiva e lingüística, e observa sua leitura documentária, constatando estratégias metacognitivas preconizadas por teóricos da leitura e estratégias específicas da atividade de análise de assunto em indexação.

As dificuldades da análise de assunto são demonstradas, a partir da influência das variáveis: texto, leitor e contexto que atuam durante $\mathrm{o}$ processo de leitura. A partir da visão interacionista do processo de leitura, demonstra que o indexador refere-se a suas dificuldades na identificação de conceitos durante a análise de assunto e revela, além do contexto profissional em que atua um outro lado do indexador que influencia sua leitura e o torna um leitor profissional: seus objetivos de indexação, sua atuação e formação profissional e suas concepções de leitura.

A concepção original do modelo de leitura documentária por Fujita (2003) baseou-se em ensaio teórico, a partir de subsídios dos estudos de estrutura textual, existência de propostas de modelos de leitura, fundamentos da análise conceitual do PRECIS e a abordagem sistemática da Norma 12.676.

O modelo de leitura obtido (Quadro 2) consiste, fundamentalmente, na combinação das metodologias de identificação de conceitos a partir de questionamento básico sobre quem, que, como, quando e onde (primeira e segunda colunas) e a localização desses conceitos em partes da estrutura textual dos documentos que contém as respostas para as questões (terceira coluna): 


\begin{tabular}{|c|c|c|}
\hline $\begin{array}{l}\text { Conceito } \\
\text { (análise conceitual) }\end{array}$ & $\begin{array}{l}\text { Questionamento } \\
\text { (norma 12.676) }\end{array}$ & $\begin{array}{l}\text { Parte da estrutura } \\
\text { textual }\end{array}$ \\
\hline Objeto & $\begin{array}{l}\text { O documento possui em seu contexto um objeto sob efeito de } \\
\text { uma atividade? }\end{array}$ & $\begin{array}{l}\text { Introdução } \\
\text { (objetivos) }\end{array}$ \\
\hline Ação & $\begin{array}{l}\text { O assunto contém um conceito ativo (por exemplo, uma ação, } \\
\text { uma operação, um processo etc.)? }\end{array}$ & $\begin{array}{l}\text { Introdução } \\
\text { (objetivos) }\end{array}$ \\
\hline Agente & O documento possui um agente que praticou esta ação? & $\begin{array}{l}\text { Introdução } \\
\text { (objetivos) }\end{array}$ \\
\hline Métodos do agente & $\begin{array}{l}\text { Este agente refere-se a modos específicos para realizar a } \\
\text { ação (por exemplo, instrumentos especiais, técnicas ou } \\
\text { métodos)? }\end{array}$ & Metodologia \\
\hline Local ou ambiência & $\begin{array}{l}\text { Todos estes fatores são considerados no contexto de um } \\
\text { lugar específico ou ambiente? }\end{array}$ & Metodologia \\
\hline Causa e efeito & $\begin{array}{l}\text { São identificadas algumas variáveis dependentes ou } \\
\text { independentes? }\end{array}$ & $\begin{array}{l}\text { Resultados; } \\
\text { discussão de } \\
\text { resultados }\end{array}$ \\
\hline $\begin{array}{l}\text { Ponto de vista do } \\
\text { autor; perspectiva }\end{array}$ & $\begin{array}{l}\text { O assunto foi considerado de um ponto de vista, } \\
\text { normalmente não associado com o campo de estudo (por } \\
\text { exemplo, um estudo sociológico ou religioso)? }\end{array}$ & Conclusões \\
\hline
\end{tabular}

Quadro 2. Modelo de leitura documentária para textos científicos: identificação de conceitos por questionamento em partes da estrutura textual (Fujita, 2003)

A compreensão e procedimentos de uso do Modelo de Leitura Documentária são facilitados por explicações orientadas por um Manual explicativo que conceitua e orienta a leitura documentária de textos científicos em três etapas: exploração da estrutura textual, identificação de conceitos e seleção de conceitos (Fujita, Rubi, 2006). Em cada uma destas etapas os procedimentos são esclarecidos um após o outro, deixando transparecer uma preparação conceitual e filosófica sobre indexação, considerando-se que a atitude do indexador, ao realizar a análise de um texto com fins de indexação, está diretamente vinculada à concepção de análise adquirida durante sua formação educacional e à política do sistema.

Resultados de pesquisas que investigaram a aplicabilidade do modelo de leitura documentária original na indexação de artigos de periódicos por profissionais indexadores (Fujita, Rubi, 2006; Fujita, 2007) demonstraram sua importância para o processo de análise de assunto e indicaram, entre outras, a recomendação de que o uso do modelo de leitura fosse vinculado à formação inicial do indexador para tornar-se prática constante, pois existirão dificuldades em seguir a estrutura do modelo de leitura, caso o indexador já tenha outra sistemática de indexação e pouco contato com o modelo.

A partir da proposição de investigar a aplicabilidade do Modelo de Leitura Documentária e de seu Manual Explicativo como recurso de aprendizagem no ensino de indexação para indexado- res aprendizes em Curso de Graduação foi desenvolvida a pesquisa "A leitura documentária na formação inicial do indexador" (2) (Fujita, 2007) que conduziu as aplicações em sala de aula durante o desenvolvimento da disciplina "Indexação" para obtenção de procedimentos e resultados de avaliação durante a tarefa de análise de assunto de artigos científicos.

Os resultados obtidos indicaram recomendações para a adequação do Modelo de Leitura Documentária e do Manual Explicativo como recursos pedagógicos tendo em vista os resultados de sua aplicabilidade com alunos do Curso de Graduação em Biblioteconomia em 11 coletas de dados. As recomendações obtidas proporcionaram a elaboração de uma versão adaptada do Modelo de Leitura Documentária que resultou na inclusão de orientações externas mais detalhadas de uso e de modificações de denominações internas com a finalidade de alcançar mais clareza para facilitar a compreensão de indexadores aprendizes no ensino de Indexação em Cursos de Graduação de Biblioteconomia.

$\mathrm{Na}$ versão adaptada do Modelo de Leitura Documentária (Anexo C) observa-se acima do quadro, uma síntese dos procedimentos descritos no manual explicativo como um "passo-apasso" solicitado pelos alunos quando do uso para o processo de indexação de artigos científicos. Esse passo-a-passo foi incluído junto ao Modelo de Leitura Documentária para ajudar o aluno a lembrar-se da seqüência de procedi- 
mentos necessários e ter orientações práticas de identificação e seleção de conceitos do conteúdo documentário no momento em que estiver realizando a tarefa de análise de assunto para indexação.

O Manual Explicativo na versão adaptada passou a ser "Manual de Ensino do Modelo de Leitura Documentária" (Fujita, 2007) por conter além da explicação dos três procedimentos de análise de assunto: exploração da estrutura textual, identificação de conceitos e seleção dos conceitos, exemplos retirados de textos das três áreas de conhecimento - ciências biológicas, ciências exatas e ciências humanas - com a finalidade de demonstração prática de seu uso para que o aluno observe seu funcionamento em diferentes áreas.

\section{O uso do modelo de leitura documentária no ensino do processo de indexação: avaliação comparada}

É necessária uma constante avaliação da aplicabilidade do modelo de leitura documentária no ensino do processo de análise de assunto a partir da experiência de uso de alunos aprendizes de indexação tendo em vista, de um lado, a complexidade que envolve o processo de análise de assunto de documentos de diferentes áreas do conhecimento e com diferentes tipologias e estruturas textuais e, de outro lado, o fato de o aprendiz não ter a vivência da atuação profissional e, em conseqüência, a definição dos objetivos profissionais que o motivariam para a tarefa de indexação.

O Modelo de Leitura Documentária, em versão adaptada (Anexo C), foi adequado com base em recomendações obtidas em pesquisas sobre sua aplicabilidade com alunos do Curso de Graduação em Biblioteconomia e utilizado nesta pesquisa comparada com alunos dos Cursos de Biblioteconomia da UNESP e da UFRGS.

O estudo de avaliação comparada foi realizado com 4 alunos da UNESP e 4 alunos da UFRGS e partiu da leitura antecipada do "Manual de Ensino do Modelo de Leitura Documentária" (FUJITA, 2007) Após a leitura do Manual, os alunos realizaram a análise de assunto conforme orientação do Modelo de Leitura a partir dos seguintes procedimentos estabelecidos pelas Professoras de Indexação dos Cursos de Biblioteconomia da UNESP e da UFRGS (3).

As coletas de dados foram realizadas na $U$ NESP - Faculdade de Filosofia e Ciências, Campus de Marilia e na Faculdade de Biblioteconomia e Comunicação (FABICO) da UFRGS. Considerando-se a necessidade de familiarida- de com o método do Modelo de Leitura Documentária, a Professora da UFRGS efetuou um teste piloto com 3 alunos do $4^{\circ}$ semestre do Curso de Biblioteconomia. A partir da observação de todo o processo e principalmente do preenchimento do formulário do Modelo de Leitura Documentária foi possível o domínio de informações mais detalhadas sobre a metodologia a ser utilizada. Antes da familiarização aconteceu contato com a Professora da UNESP, idealizadora do método do Modelo, para esclarecimentos teóricos e metodológicos.

Nas duas coletas os participantes da pesquisa foram:

UFRGS - quatro alunos do terceiro semestre, pelo fato de já terem cursado as disciplinas de Fundamentos de Organização e Tratamento da Informação ( $1^{\circ}$ semestre) e de Introdução à Representação Temática $\left(2^{\circ}\right.$ semestre $)$ nas quais são apresentados os sistemas de classificação, bem como noções de categorias, mapas conceituais, análise facetada e exercícios de indexação, momento em que aliam a leitura do texto à determinação de palavras-chaves.

UNESP - uma aluna da graduação em Biblioteconomia, experiente em indexação e no modelo de leitura e três alunos, do $6^{\circ}$ semestre por estarem cursando a disciplina de "Indexação" e terem a familiaridade com o Modelo de Leitura Documentária.

Conforme parâmetro de avaliação comparada da pesquisa foi possível ter um grupo de alunos com familiaridade no uso do Modelo de Leitura Documentária (Grupo de controle - UNESP) e um grupo de alunos sem familiaridade (Grupo de ação - UFRGS). A tarefa utilizada para avaliação comparada foi realizada visando aos objetivos da metodologia de identificação e seleção de conceitos em análise de assunto do Modelo de Leitura Documentária para a indexação de artigos científicos.

Para as duas aplicações do Modelo de Leitura Documentária, foram selecionados dois artigos do periódico Revista Pró-fono da área de Fonoaudiologia (4) que apresentam a seguinte estrutura: Títulos, Autores, Resumo, Palavras-chave, Abstract, Keywords, Introdução, Material e Métodos, Resultados e Discussão, Conclusões e Referências. Cada professora selecionou um artigo diferente da área de Fonoaudiologia cuja estrutura fosse familiar para a localização de partes da estrutura do texto, possibilitando maior rapidez na identificação das categorias.

Em uma rápida análise da tarefa, observa-se que o conteúdo do artigo selecionado para o Grupo da UNESP tem como objetivo descrever 
a evolução do padrão de sucção e os efeitos da sucção não nutritiva (SNN) em recém nascidos pré-termo (RNPT), adequados para a idade gestacional (AIG), em função do avanço da idade gestacional (IG) corrigida, considerando que os padrões de SNN e sucção nutritiva (SN) se modificam à medida em que ocorre a maturação desta função ao longo do tempo e que a estimulação da SNN poderá contribuir para uma maturação mais rápida da $\mathrm{SN}$ e pode ser influenciada pelo método de estimulação utilizado.

No Quadro 3 é possível verificar como fica o resultado da análise da tarefa de identificação de termos do artigo selecionado para o Grupo UNESP

\begin{tabular}{|c|c|}
\hline Conceito & Termos identificados \\
\hline Objeto & $\begin{array}{l}\text { Recém-nascido pré- } \\
\text { termo }\end{array}$ \\
\hline Ação & Sucção \\
\hline
\end{tabular}

Agente Sucção não nutritiva

$\begin{array}{ll}\text { Métodos do agente } & \begin{array}{l}\text { Dedo enluvado } \\ \text { Chupeta }\end{array} \\ \text { Local ou ambiência } & \text { Berçário anexo à } \\ & \text { maternidade do HC - } \\ & \text { Serviço de Pediatria } \\ & \text { Clínica, Intensiva e } \\ & \text { Neonatal - Instituto da } \\ & \text { Criança - FMUSP } \\ & \text { CAUSA: sucção de } \\ & \text { recém nascido pré- } \\ \text { Causa e efeito } & \text { termo; } \\ & \text { EFEITO: } \\ & \text { fortalecimento da } \\ & \text { sucção; } \\ & \text { maturação da } \\ \text { capacidade de sucção }\end{array}$

Quadro 3: Termos identificados no artigo do Grupo UNESP para análise da tarefa

No texto selecionado para a tarefa do Grupo da UFRGS, seu conteúdo traz como objetivo geral analisar aspectos relevantes do desenvolvimento da consciência fonológica em vinte escolares de primeiras e segundas séries do ensino público fundamental com os objetivos específicos de verificar o efeito de um programa fonoaudiológico preventivo em linguagem oral e escrita no desenvolvimento da consciência fonológica e verificar evolução da consciência fonológica.

No Quadro 4 é possível verificar como fica o resultado da análise da tarefa de identificação de termos do artigo selecionado para o Grupo UFRGS.

\begin{tabular}{|c|c|}
\hline Conceito & Termos identificados \\
\hline Objeto & $\begin{array}{l}\text { Crianças de } 1^{a} \text { e } 2^{a} \\
\text { série }\end{array}$ \\
\hline Ação & $\begin{array}{l}\text { Consciência } \\
\text { fonológica }\end{array}$ \\
\hline Agente & $\begin{array}{l}\text { Programa } \\
\text { Fonoaudiológico } \\
\text { preventivo }\end{array}$ \\
\hline Métodos do agente & $\begin{array}{l}\text { Protocolo de } \\
\text { letramento } \\
\text { Protocolo de } \\
\text { consciência } \\
\text { fonológica. }\end{array}$ \\
\hline Local ou ambiência & $\begin{array}{l}\text { Escola Estadual de } \\
\text { Ensino Fundamental }\end{array}$ \\
\hline Causa e efeito & $\begin{array}{l}\text { CAUSA: Consciência } \\
\text { fonológica de crianças } \\
\text { de } 1^{\mathrm{a}} \text { e } 2^{\mathrm{a}} \text { série } \\
\text { EFEITO: Alfabetização; } \\
\text { Letramento }\end{array}$ \\
\hline
\end{tabular}

Quadro 4. Termos identificados no artigo do Grupo UFRGS para análise da tarefa

Os procedimentos iniciais e anteriores à aplicação do Modelo de Leitura Documentária para a tarefa de indexação do artigo científico da área de Fonoaudiologia foram diferentes para o Grupo da UNESP e para o Grupo da UFRGS, tendo em vista o grau de familiarização dos alunos.

Os procedimentos de aplicação do Modelo de Leitura Documentária para a tarefa de indexação do artigo científico da área de Fonoaudiologia foram idênticos para o Grupo da UNESP e para o Grupo da UFRGS, com exceção dos procedimentos iniciais, tendo em vista o grau de familiarização dos alunos.

Para o Grupo da UFRGS, inicialmente explicouse o formulário da pesquisa, seu objetivo, o modelo de leitura para extrair os conceitos dos textos científicos, detalhando-se o significado das categorias, os questionamentos a serem utilizados, bem como a parte da estrutura textual relacionada. Esses procedimentos iniciais foram acompanhados de discussões e explicações com os alunos para oportunizar que todos expressassem as dúvidas.

Para o Grupo da UNESP foi entregue o Manual de Ensino do Modelo de Leitura para indexação 
de textos científicos no dia anterior à coleta de dados. No dia da aplicação, levaram o Manual de Ensino e receberam o artigo selecionado e o Modelo de Leitura Documentária (Anexo C).

Ao serem solicitados a realizar a tarefa de indexação com o Modelo de Leitura Documentária, os alunos da UNESP e da UFRGS passaram a realizar a identificação dos termos conforme a grade do modelo apresentada para preenchimento da coluna dos termos identificados. Observou-se que os alunos dos dois grupos iniciaram a leitura do artigo científico utilizando o seu conhecimento prévio e a metodologia do Modelo de leitura para auxílio da atividade a partir de uma leitura das partes do artigo com o intuito de entendimento do assunto, bem como para identificação dos termos tendo em vista os conceitos propostos pelo modelo.
No entanto, vale ressaltar que o fato de os alunos da UNESP terem familiaridade com o Modelo de Leitura Documentária e, conseqüentemente, uma maior compreensão dos conceitos e sua possível localização dentro da estrutura textual, não sentiram a necessidade de consultar as orientações do Modelo de Leitura na identificação dos termos.

Ao término da atividade realizaram-se entrevistas retrospectivas com os alunos a fim de solicitar o relato de suas dúvidas, dificuldades e indicação de sugestões ao aprimoramento do Modelo de Leitura Documentária.

Para análise dos resultados verificaram-se, em análise comparativa dos alunos de cada Grupo, os termos identificados durante o uso do Modelo de Leitura Documentária. Os Quadros 5 e 6 referem-se, respectivamente, ao Grupo UFRGS e Grupo UNESP.

\begin{tabular}{|c|c|c|c|c|}
\hline Conceito & Aluno 1 & Aluno 2 & Aluno 3 & Aluno 4 \\
\hline Objeto & Consciência fonológica & Crianças de $1^{\mathrm{a}}$ e $2^{\mathrm{a}}$ série & $\begin{array}{l}\text { Consciência } \\
\text { fonológica } \\
\text { Alunos de Ensino } \\
\text { Fundamental }\end{array}$ & $\begin{array}{l}\text { Consciência } \\
\text { fonológica }\end{array}$ \\
\hline Ação & Evolução & $\begin{array}{l}\text { Verificar o efeito de um } \\
\text { programa fono } \\
\text { audiologico preventivo }\end{array}$ & Evolução & $\begin{array}{l}\text { Evolução } \\
\text { Desenvolvimento }\end{array}$ \\
\hline Agente & - & $\begin{array}{l}\text { Programa } \\
\text { Fonoaudiologico Escolar }\end{array}$ & - & - \\
\hline $\begin{array}{l}\text { Método do } \\
\text { Agente }\end{array}$ & $\begin{array}{l}\text { Seleção de } 20 \text { Alunos } \\
\text { com pior desenvolvi- } \\
\text { mento na avaliação de } \\
\text { letramento na } 1^{\mathrm{a}} \text { e } 2^{\mathrm{a}} \\
\text { série } \\
\text { Aplicação do protocolo } \\
\text { de desempenho e } \\
\text { consciência fonológica } \\
\text { antes e depois de } \\
\text { sessões de estimulação. }\end{array}$ & $\begin{array}{l}\text { Protocolo de letramento } \\
\text { e consciência } \\
\text { fonológica. } \\
\text { Código escrito. } \\
\text { Leitura de palavras e } \\
\text { frases. }\end{array}$ & $\begin{array}{l}\text { Protocolo de } \\
\text { letramento. } \\
\text { Protocolo de } \\
\text { consciência fonológica }\end{array}$ & $\begin{array}{l}\text { Protocolo de } \\
\text { letramento. } \\
\text { Protocolo de } \\
\text { consciência fonológica }\end{array}$ \\
\hline $\begin{array}{l}\text { Local ou } \\
\text { ambiência }\end{array}$ & $\begin{array}{l}\text { Escola Estadual } \\
\text { São Paulo }\end{array}$ & $\begin{array}{l}\text { Escola Estadual } \\
\text { São Paulo }\end{array}$ & $\begin{array}{l}\text { Escola Estadual de } \\
\text { Ensino Fundamental }\end{array}$ & $\begin{array}{l}\text { Escola Estadual } \\
\text { Ensino Fundamental }\end{array}$ \\
\hline $\begin{array}{l}\text { Causa e } \\
\text { Efeito }\end{array}$ & $\begin{array}{l}\text { Aumento da consciência } \\
\text { fonológica após a } \\
\text { realização de sessão de } \\
\text { estímulos. }\end{array}$ & $\begin{array}{l}\text { Programa de } \\
\text { fonoaudiologia } \\
\text { Escolares. }\end{array}$ & $\begin{array}{l}\text { Alfabetização. } \\
\text { Letramento }\end{array}$ & $\begin{array}{l}\text { Alfabetização. } \\
\text { Letramento. }\end{array}$ \\
\hline
\end{tabular}

Quadro 5: Termos identificados pelos alunos do Grupo UFRGS

\begin{tabular}{|c|c|c|c|c|}
\hline Conceito & Aluno 1 & Aluno 2 & Aluno 3 & Aluno 4 \\
\hline Objeto & Recém-nascidos & Recém-nascidos & $\begin{array}{l}\text { Recém-nascidos pré- } \\
\text { termos }\end{array}$ & Recém-nascidos \\
\hline Ação & Estimulação & Sucção & Sucção & Sucção \\
\hline Agente & Sucção & Recém-nascidos & ---- & Sucção não nutritiva \\
\hline $\begin{array}{l}\text { Método do } \\
\text { Agente }\end{array}$ & $\begin{array}{l}\text { Chupeta ortodôntica, } \\
\text { Estimulação da } \\
\text { sucção não } \\
\text { nutritiva(SNN), }\end{array}$ & $\begin{array}{l}\text { Chupeta ortodôntica, } \\
\text { Mini mamadeira e } \\
\text { Dedo enluvado }\end{array}$ & $\begin{array}{l}\text { Chupeta ortodôntica, } \\
\text { Sucção não } \\
\text { nutritiva(SNN), } \\
\text { Dedo enluvado }\end{array}$ & $\begin{array}{l}\text { Chupeta ortodôntica, } \\
\text { Mini mamadeira e } \\
\text { Dedo enluvado }\end{array}$ \\
\hline
\end{tabular}




\begin{tabular}{|c|c|c|c|c|}
\hline & Dedo enluvado & & & \\
\hline $\begin{array}{l}\text { Local ou } \\
\text { ambiência }\end{array}$ & $\begin{array}{l}\text { Berçário anexo a } \\
\text { Maternidade do HC da } \\
\text { FMUSP entre abril de } \\
2000 \text { e janeiro de } 2002\end{array}$ & $\begin{array}{l}\text { Escola Estadual } \\
\text { São Paulo }\end{array}$ & $\begin{array}{l}\text { Maternidade do } \mathrm{HC} \text { da } \\
\text { FMUSP }\end{array}$ & HC da FMUSP \\
\hline $\begin{array}{l}\text { Causa e } \\
\text { Efeito }\end{array}$ & $\begin{array}{l}\text { Causa: Estimulação } \\
\text { de recém-nascidos; } \\
\text { Efeito: Evolução no } \\
\text { padrão de sucção }\end{array}$ & $\begin{array}{l}\text { Programa de } \\
\text { fonoaudiologia } \\
\text { Escolares. }\end{array}$ & $\begin{array}{l}\text { Causa: Sucção de } \\
\text { recém-nascidos pré- } \\
\text { termos; } \\
\text { Efeito: Evolução no } \\
\text { padrão de sucção }\end{array}$ & $\begin{array}{l}\text { Causa: Sucção de } \\
\text { recém-nascidos pré- } \\
\text { termos; } \\
\text { Efeito: Estimulação da } \\
\text { sucção não nutritiva } \\
\text { (SNN), com o dedo } \\
\text { enluvado }\end{array}$ \\
\hline
\end{tabular}

Quadro 6: Termos identificados pelos alunos do Grupo UNESP

Os resultados obtidos das duas aplicações, com o Grupo UNESP e o Grupo UFRGS, demonstraram que a categorização utilizada pelo Modelo de Leitura Documentária colabora, de modo geral, com a uniformidade dos conceitos identificados e com os procedimentos de análise de assunto para indexação deixando claro quais as etapas a serem realizadas e qual a seqüência delas.

No Grupo UFRGS (Quadro 5), observa-se que, contrariamente às orientações que antecedem o Modelo de Leitura Documentária, alguns alunos identificaram enunciados ou frases ao invés de termos mais específicos, como por exemplo, "Verificar o efeito de um programa fonoaudiológico preventivo" ao invés de "programa fonoaudiológico preventivo". Para um indexador proficiente, não seria possível identificar como termo específico uma frase inteira, pois ele pensaria na demanda do usuário durante a estratégia de busca, ou seja, nunca o usuário buscaria por uma frase e sim por "programa fonoaudiológico preventivo" ou "fonoaudiologia preventiva". Por isso, no passo-a-passo do Modelo de Leitura Documentária (Anexo C) existe a orientação de que "os três conceitos principais deverão ser representados por apenas um termo cada". Nesse sentido é importante considerar que o aluno nunca teve contato com a política de indexação de sistemas de recuperação da informação e, por isso, não antevê a demanda do usuário na definição dos termos, senão pensaria na necessidade de ter especificidade durante a indexação.

O termo evolução, considerado nas orientações do Modelo de Leitura Documentária como termo vazio, foi utilizado pelos alunos para representar a categoria Ação. O que demonstra a necessidade de continuidade e ênfase no uso constante do modelo durante o ensino do processo de análise de assunto para indexação para que sua metodologia seja assimilada e compreendida.
De acordo com a Professora da UFRGS, os alunos tiveram a tendência de utilizar as palavras chave do artigo. Conforme seu relato, ela entende que, talvez seja pelo hábito adquirido nas disciplinas de $1^{\circ}$ e $2^{\circ}$ semestre do Curso de Biblioteconomia da FABICO/UFRGS em exercícios de análise de assunto nos quais se destaca a leitura textual e a determinação de palavraschave.

Além disso, os alunos se confundiram e revelaram dificuldades na compreensão das categorias "Ação", "Objeto" e "Agente" conforme orientações do Modelo de Leitura e do Manual de Ensino, o que significa que o processo de análise de assunto por meio da análise conceitual deve ser revista objetivando-se uma adequação da metodologia, pois os alunos sentem grande dificuldade neste ponto.

Entretanto, esta dificuldade propicia uma reflexão dos professores de indexação, no sentido de uma ênfase no estudo das categorias para a análise conceitual.

A Professora considera ainda que a metodologia do Modelo de leitura documentária para indexação de artigos científicos orienta o aluno na busca de conceitos em partes da estrutura textual e possibilita a definição de uma metodologia de trabalho para o processo de análise de assunto e identificação do assunto do documento. Por outro lado constatou como dificuldade da aplicabilidade a etapa de tradução tendo em vista que o DECS - Descritores na Área da Saúde não dispõe de termos específicos na área de Fonoaudiologia.

No Grupo UNESP, apesar da atividade ter sido respaldada pelo Modelo de Leitura Documentária para indexação de textos científicos e de seu Manual de Ensino, obteve-se resultados bastante diversificados entre os alunos como demonstra o Quadro 6. Dois alunos iniciaram a indexação do artigo, de modo estratégico, lendo o título, o começo da introdução e se prenderam no objetivo do trabalho para a localização dos 
três primeiros conceitos, assim como o modelo sugere em suas orientações. Entretanto, mesmo tendo o Modelo de Leitura em mãos, os quatro alunos ainda ficaram em dúvida para designar os termos representativos dos três primeiros conceitos (objeto, ação e agente), sendo que os resultados quanto aos termos identificados para o conceito agente são diferentes entre os quatro. A Professora da UNESP considera que os alunos precisam aprender a lidar com as diferenças entre os conceitos principais, ou seja, ação e agente. A dúvida sobre qual termo representaria a ação, conseqüentemente, levou os alunos a não conseguirem responder prontamente qual era a causa e o efeito, uma vez que estes conceitos são identificados a partir dos termos que representam os conceitos ação mais o objeto.

Por outro lado, os alunos conseguiram encontrar com facilidade os métodos do agente que são os métodos, técnicas e equipamentos utilizados para a realização da pesquisa, e também o local e ambiência, que é o local físico onde foi realizada a pesquisa. Os conceitos de causa e efeito foram alvo de dificuldades quanto ao entendimento de que a causa seria representada pela soma dos termos identificados como ação e objeto e, em seguida, responder à questão sobre qual era o efeito desta causa.

Com a comparação dos Quadros 3 e 4 de análise da tarefa dos artigos indexados, respectivamente, pelos alunos da UNESP (Grupo de controle) e da UFRGS (Grupo de ação), observamos, a partir dos Quadros 5 e 6, que o Grupo de controle (UNESP), apesar de apresentar dificuldades na representação dos conceitos, identificou termos específicos, evitou termos vazios de significado e obteve compatibilidade nos termos identificados nas categorias do Modelo de Leitura Documentária, tendo em vista a experiência e familiaridade desses alunos com o método.

Esse resultado comparado com o Grupo de ação (UFRGS) reitera a necessidade, apontada pela Professora da UFRGS, de o uso do Modelo de Leitura Documentária ser antecipado e acompanhado de explicações detalhadas sobre sua aplicabilidade, sobretudo quanto ao método de análise conceitual.

Em síntese, pode ser afirmado que o exercício da leitura em sala de aula, nesta área, é de fundamental importância, pois vai proporcionar ao discente a internalização das estruturas cognitivas essenciais para outros tipos de leitura necessários, tornando os futuros bibliotecários mais competentes para as complexas elaborações mentais, características de sua atividade profissional. (Ferreira, G. I. S.; Bonotto, M. E. K.; van der Laan, R. H., 2007)
A experiência de uso contínuo e a familiaridade com o método são necessárias para que o aluno saiba lidar com as dificuldades da leitura documentária para análise de assunto na indexação de conteúdos documentários de diferentes áreas de assunto cujo domínio terá que ser resolvido pelo conhecimento prévio do indexador na atividade contínua de indexação.

\section{Considerações finais}

Conclui-se que o ensino do processo de análise de assunto necessita de reflexões conjuntas entre docentes dos Cursos de Biblioteconomia para compartilhamento de conhecimentos teóricos e metodológicos e decisões quanto ao desenvolvimento e seqüência de conteúdo curricular e atividades práticas na disciplina de Indexação de modo a propiciar vivências aproximadas do contexto de atuação profissional.

A avaliação comparada foi válida uma vez que propiciou a visão e discussão de metodologias de ensino entre alunos e professores. Esta prática também sinalizou a necessidade de uma maior ênfase no estudo das categorias e evidenciou a utilidade do uso das mesmas em análises de assunto como forma de auxiliar 0 aluno na identificação dos assuntos dos documentos.

\section{Referencias}

ABNT. (1992) Métodos de Análise de Documentos: seleção de termos de indexação. Rio de Janeiro, 1992. (NBR 12676)

Ferreira, g. I. S.; Bonotto, M. E. K.; van der Laan, R. H. (2007) A presença da leitura na área de Organização e Tratamento da Informação. In: SANTOS, J. P. (org.) A leitura como prática pedagógica na formação do profissional da informação. Rio de Janeiro: Fundação Biblioteca Nacional; ABECIN, 2007. p. 91-99.

Fujita, M. S. L. (2003) A leitura documentária do indexador: aspectos cognitivos e lingüísticos influentes na formação do leitor profissional. 2003. 321f. Tese (Livre-Docência em Análise Documentária e Linguagens Documentárias Alfabéticas) - Faculdade de Filosofia e Ciências, UNESP.

Fujita, M. S. L. (2007) A leitura documentária na formação inicial do indexador: a abordagem sociocognitiva na investigação de estratégias de ensino. Marília: Departamento de Ciência da Informação, Faculdade de Filosofia e Ciências, 2007. 272f (Relatório Final de Pesquisa desenvolvida no período de março de 2004 a fevereiro de 2007 com Bolsa de Produtividade em Pesquisa ao CNPq)

Fujita, M. S. L., Rubi, M. P. (2006) Modelo de lectura profesional para la indización de textos científicos. Scire, Zaragoza, v.12, n.1, p. 47-70, enero-junio 2006.

Lancaster, F. W. (2004) Indexação e resumos: teoria e prática. 2.ed.rev.atual. Brasília: Briquet de Lemos Livros, 2004. Tradução de Antonio Agenor Briquet de Lemos. $452 p$. 


\section{Notas}

(1) A coleta de dados da aplicação do Modelo de Leitura Documentária no Curso de Biblioteconomia da UNESP de Marília teve a colaboração das bolsistas de Iniciação Científica do CNPq Mariana de Oliveira Inácio (marianaoi@marilia.unesp. br); Daniela Majorie dos Reis (danielamajorie@marilia.unesp. br); e Cristina Miyuki Narukawa (cnarukawa@marilia.unesp. br)

(2) Projeto Integrado de Pesquisa "A leitura documentária na formação inicial do indexador: a abordagem sociocognitiva na investigação de estratégias de ensino", desenvolvido no período de
2004/2007, sob coordenação de Mariângela Spotti Lopes Fujita e com apoio do CNPq

(3) Professora da UNESP: Mariângela Spotti Lopes Fujita; Professora da UFRGS: Glória Isabel Sattamini Ferreira

(4) Artigo UNESP: NEIVA, F. C. B; LEONE, C. R. Sucção em recém-nascidos pré-termo e estimulação da sucção. Revista Pró-fono R. Atual Científica, 18:2, 2006.

Artigo UFRGS: CARNIO, Maria Sílvia; SANTOS, Daniele dos. Evolução da consciência fonológica em alunos do ensino fundamental. Pró-Fono R. Atual. Cient., Barueri, v. 17, n. 2, 2005.

\section{Anexo A}

Plano de ensino

Disciplina: "Indexação" (30 horas/aulas)

$2^{\circ}$ semestre do $3^{\circ}$ ano do Curso de Biblioteconomia (UNESP-Campus de Marília)

\section{Ementa:}

A indexação como operação documentária de tratamento temático de conteúdo. Processo de indexação: da identificação, seleção e representação de conceitos. Análise de assunto e tematicidade: influência das concepções de análise de assunto. Os sistemas de indexação e a representação na análise de assunto. Política de indexação em unidades e sistemas de informação.

\section{Objetivos:}

Realizar análise de conteúdos documentários segundo concepção orientada para o conteúdo e para a demanda aplicando metodologias de indexação;

Realizar a representação de conteúdos temáticos de documentos técnicos e científicos mediante identificação e seleção de conceitos.

\section{Conteúdo programático}

1. Tratamento da informação: conceituação, operações e produtos

2. Indexação: contexto e função

3. Política de indexação

40 processo de indexação

4.1 Identificação e seleção de conceitos

\subsubsection{Análise de assunto e tematicidade}

4.1.2 Concepções de análise de assunto

4.2 Metodologia de identificação de conceitos e exploração da estrutura textual em indexação

5 Indexação automática.

\section{Critérios de avaliação:}

Serão avaliados o exercício de indexação da base LILACS, os Seminários sobre Indexação automática, os Exercícios práticos de indexação de artigos de periódicos e o trabalho prático sobre elaboração de política de indexação. 
Plano de aulas

Dia 00/00/0000

1. Tratamento da informação: conceituação, operações e produtos

Texto recomendado para leitura: GUIMARÃES, J. A. C. A análise documentária no âmbito do tratamento da informação: elementos históricos e conceituais. In: RODRIGUES, G. M.; LOPES, I. L. (Org.) Organização e representação do conhecimento na perspectiva da Ciência da Informação. Brasília: Thesaurus, 2003. p. 100-118.

Apresentação do conteúdo em transparências

Dia 00/00/0000

2. Indexação: contexto e função

Texto recomendado para leitura: CHAUMIER, J. Indexação; conceito, etapas, instrumentos. Revista Brasileira de Biblioteconomia e Documentação, v.21, n.1/2, p:63-79, jan./jun. 1988

Avaliação: Exercício de indexação da base LILACS com a participação de Vera Regina Casari Boccato. (Valor: 1,0)

Dias 00/00 a 00/00/0000

3. Política de indexação

Textos recomendados:

Rubi, M. P. ; Fujita, M. S. L. Elementos de política de indexação em manuais de indexação de sistemas de informação especializados. Perspectivas em Ciência da Informação, Belo Horizonte, v.8, n.1, p. 6677, jan./jun. 2003.

Carneiro,M.V. Diretrizes para uma política de indexação. Revista da Escola de Biblioteconomia da UFMG, v.14, n.2, p:221-241, set. 1985.

Guimarães, J. A. C. As políticas de indexação como elemento para a gestão do conhecimento nas organizações. In: Vidotti, S. A. G. (Coord.) Tecnologia e conteúdos informacionais: abordagens teóricas e práticas. São Paulo: Polis, 2004. p. 43-52.

Avaliação: Dinâmica em grupo - Trabalho sobre elaboração de política de indexação para a biblioteca do Campus de Marília com aplicação de Protocolo Verbal em Grupo. (Valor: 3,0)

Palestrante convidada: Milena Polsinelli Rubi

Dia 00/00/0000

50 processo de indexação

5.1 Identificação e seleção de conceitos

5.1.1 Análise de assunto e tematicidade

\subsubsection{Concepções de análise de assunto}

Texto recomendado para leitura: Fujita, Mariângela Spotti. Lopes. A identificação de conceitos no processo de análise de assunto para indexação. Revista Digital de Biblioteconomia e Ciência da Informação, Campinas, v. 1, n. 1, jul. 2003. Disponível em: http://bibli.fae.unicamp. br/revbib/index.html

Apresentação do conteúdo em transparências

Avaliação: Dinâmica de grupo - Redigir comentário reflexivo sobre análise de assunto em indexação, tematicidade e concepções de análise de assunto na formação profissional em indexação. Entregar até dia (Valor: 2,0)

Dias 00/00 a 00/00/0000

5.2 Metodologia de identificação de conceitos e exploração da estrutura textual em indexação 
Texto recomendado para leitura: Manual Explicativo do Modelo de leitura para indexação de textos científicos

Apresentação do conteúdo: Modelo de lectura

Avaliação: Dinâmica entre 2 alunos em cada computador: Indexar 3 artigos de periódicos científicos e 1 livro aplicando Modelo de Leitura Documentária para indexação de textos científicos, constante do manual explicativo e preenchendo o quadro disponível para esse fim. Redigir relato de dificuldades na interação para a indexação dos artigos e do livro. Este exercício será realizado em sala de aula. (Valor: 2,0)

\section{Dia 00/00/0000}

6 Indexação automática.

Texto recomendado para leitura: Gil Leiva, Isidoro La automatización de la indización de documentos. Gijón: Ediciones Trea, 1999.

Dinâmica de grupo: Seminários de partes do texto para cada grupo (Valor: 2,0)

\section{Anexo B}

\section{Disciplinas da Área de Organização e Tratamento da Informação Curso de Biblioteconomia - FABICO/UFRGS}

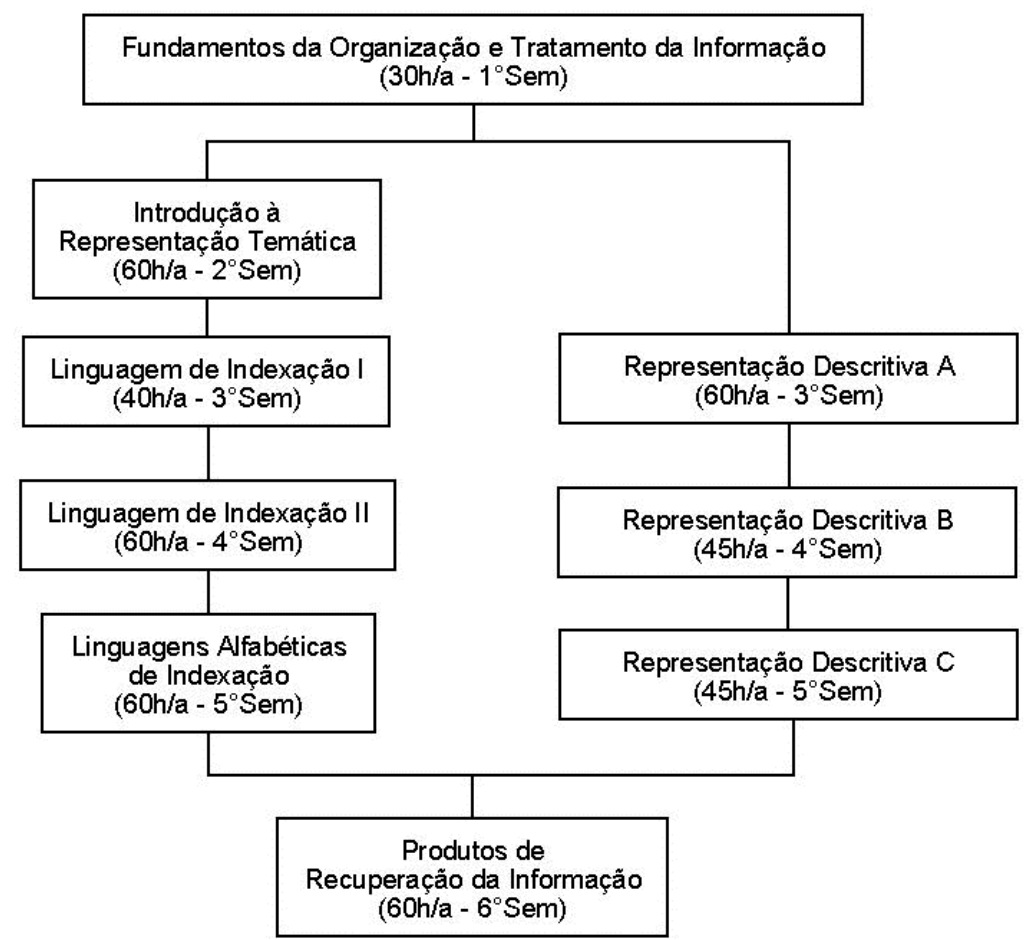

\section{Anexo C. Modelo de leitura documentária para indexação de textos científicos (versão adaptada)}

Referência do texto:

Passo-a-passo:

$1^{\circ}$ Observação da estrutura textual e localização do conteúdo do artigo científico: localizar no texto científico os elementos que o compõem, tal como, introdução, metodologia, resultados, discussão dos resultados e conclusão. Verifique o conteúdo pertinente a cada parte do texto.

$2^{\circ}$ Identificação dos conceitos: considera-se importante, observar as partes da estrutura textual e realizar o questionamento, indicados na grade do modelo de leitura, para que a identificação dos conceitos seja correta. 
Para explicações detalhadas referentes à utilização do modelo de leitura, volte ao manual explicativo;

Observações importantes:

- $\quad$ os três conceitos ação, objeto e agente são principais, estão interligados e são dependentes um do outro;

- $\quad$ conceito objeto deve ser o primeiro a ser identificado e a partir dele deverão ser identificados a ação e, em seguida, o agente, nesta ordem;

- os três conceitos principais deverão ser representados por apenas um termo cada;

- $\quad$ termos vazios de significado, como "avaliação", "estudo", "análise” e etc, não devem representar os conceitos principais e os demais conceitos;

- $\quad$ conceito ação pode ser representado por termo que denomina uma doença ou um fenômeno, como "coagulação" mas, na maioria dos textos é um verbo;

- $\quad$ nem todos os conceitos serão, necessariamente, identificados por termos.

\begin{tabular}{|c|c|c|c|}
\hline Conceitos & $\begin{array}{l}\text { Questionamento para identificação de } \\
\text { conceitos }\end{array}$ & $\begin{array}{l}\text { Partes da } \\
\text { estrutura } \\
\text { textual }\end{array}$ & $\begin{array}{l}\text { Exemplos de termos } \\
\text { identificados }\end{array}$ \\
\hline $\begin{array}{l}\text { Objeto e parte(s) do objeto } \\
\text { (algo ou alguém que está } \\
\text { sob estudo do pesquisador) }\end{array}$ & $\begin{array}{l}\text { O documento possui em seu contexto } \\
\text { um objeto sob efeito desta ação? }\end{array}$ & $\begin{array}{l}\text { Introdução } \\
\text { (objetivos) }\end{array}$ & $\begin{array}{l}\text { Flora anaeróbia + intestino } \\
\text { delgado + lactente }\end{array}$ \\
\hline $\begin{array}{l}\text { Ação (processo sofrido por } \\
\text { algo ou alguém) }\end{array}$ & $\begin{array}{l}\text { O assunto contém uma ação (podendo } \\
\text { significar uma operação, um processo } \\
\text { etc.)? }\end{array}$ & $\begin{array}{l}\text { Introdução } \\
\text { (objetivos) }\end{array}$ & Proliferação \\
\hline $\begin{array}{l}\text { Agente(aquele ou algo que } \\
\text { realizou a ação) }\end{array}$ & $\begin{array}{l}\text { O documento possui um agente que } \\
\text { praticou esta ação? }\end{array}$ & $\begin{array}{l}\text { Introdução } \\
\text { (objetivos) }\end{array}$ & $\begin{array}{l}\text { Microrganismos } \\
\text { anaeróbios }\end{array}$ \\
\hline $\begin{array}{l}\text { Métodos (métodos } \\
\text { utilizados para realização } \\
\text { da pesquisa) }\end{array}$ & $\begin{array}{l}\text { Para estudo do objeto ou } \\
\text { implementação da ação, o documento } \\
\text { cita e/ou descreve modos específicos, } \\
\text { por exemplo: instrumentos especiais, } \\
\text { técnicas, métodos, materiais e } \\
\text { equipamentos? }\end{array}$ & Metodologia & $\begin{array}{l}\text { Intubação intestinal; } \\
\text { Análise morfológica das } \\
\text { colônias }\end{array}$ \\
\hline $\begin{array}{l}\text { Local ou ambiência } \\
\text { (local físico onde foi } \\
\text { realizada a pesquisa) }\end{array}$ & $\begin{array}{l}\text { Todos estes fatores são considerados } \\
\text { no contexto de um lugar específico ou } \\
\text { ambiente? }\end{array}$ & Metodologia & $\begin{array}{l}\text { Unidades de } \\
\text { Gastroenterologia } \\
\text { pediatrica }\end{array}$ \\
\hline $\begin{array}{l}\text { Causa e efeito } \\
\text { Causa (ação+objeto)/efeito }\end{array}$ & $\begin{array}{l}\text { Considerando que a ação e o objeto } \\
\text { identificam uma causa, qual é o efeito } \\
\text { desta causa? }\end{array}$ & $\begin{array}{l}\text { Resultados; } \\
\text { discussão de } \\
\text { resultados; } \\
\text { Conclusões }\end{array}$ & $\begin{array}{l}\text { Causa: proliferação da } \\
\text { flora anaeróbia em } \\
\text { intestino delgado de } \\
\text { lactentes (ação + objeto); } \\
\text { Efeito: diarréia aguda e } \\
\text { persistente }\end{array}$ \\
\hline
\end{tabular}

